\title{
Standardizing transdifferentiation of rabbit bone marrow mesenchymal stem cells to corneal lineage by simulating corneo-limbal cues
}

\author{
Saumi Mathews ${ }^{1}$, Tilak Prasad ${ }^{1}$, Balu Venugopal ${ }^{1}$, Anwar Azad Palakkan ${ }^{1}$, Anil Kumar PR ${ }^{1}$ and Kumary TV ${ }^{*}$ \\ ${ }^{1}$ Tissue Culture Laboratory, Biomedical Technology Wing, Sree Chitra Tirunal Institute for Medical Sciences and Technology, Trivandrum, Kerala, India
}

\begin{abstract}
Corneal pathologies due to limbal stem cell deficiency or trauma is a common occurrence with high incidence in the modern era. Absence of native limbal stem cells in these cases can even result in blindness unless treated. Identifying alternate autologous stem cells with potential to replace limbal stem cells, gain its significance especially in cases of bilateral limbal damage. Here we look at the suitability of proposing bone marrow derived mesenchymal stem cells as an alternate to limbal stem cells. This work had made use of the corneo - limbal cues for trans differentiating these mesodermal cells to corneal epithelial lineage. Mesenchymal stem cells were isolated from rabbit bone marrow and the culture conditions were optimized. Characterized mesenchymal stem cells were transdifferentiated by simulating limbal niche using extracellular matrix and limbal fibroblast conditioned medium. The differentiation to corneal lineage was evaluated by analyzing the expression of mesenchymal (ABCG2, CD29) and corneal epithelial (CK3/12) markers. Cells cultured in the presence of conditioned medium alone and with conditioned medium/ extracellular matrix showed the expression of CK3/12. CK3/12 expressing cells in these cultures were increasing, with a concomitant decrease in stem cell marker expression. Trans differentiating mesenchymal stem cells to corneal epithelial like cells will provide a useful, autologous source of adult stem cells in therapeutic approaches for patients suffering from bilateral limbal stem cell deficiency.
\end{abstract}

\section{Introduction}

Visual loss is increasing in an alarmingly high rate across the globe with profound psychological, economic, social and financial consequences for the patient and the society. Cornea, the outer most layer of the eye prevents foreign body entry, protects the eye and supports vision. Cornea is made of five different layers with corneal epithelium replenished regularly by fresh epithelial cells derived from limbal stem cells (LSCs) [1]. Limbal stem cells are located within the basal layer of corneo-scleral junction called limbus [1,2]. Deficiency of LSCs due to inherited and acquired conditions prevents the reepithelialization of cornea by limbal epithelial cells resulting in conjunctivalization and vascularization that leads to visual impairment or blindness. Many efforts are made to improve the clinical prognosis and treatment for limbal stem cell deficiency (LSCD) like autologous cultured limbal epithelial transplantation (CLET), which requires limbal biopsy from contra lateral eye, which can also lead to LSCD in the normal eye. However such treatment modalities are not possible in patients with bilateral total limbal stem cell deficiency conditions. In bilateral cases, allogeneic limbal epithelium harvested either from living related donors or cadaveric donor eyes may be used for transplantation in combination with long term immunosuppressive therapy. This approach has a very low success rate as compared with autologous cells mostly followed by implant rejection. Therefore, alternative stem cell-based therapeutic strategies for ocular surface reconstruction are required and is in focus. Ex vivo expansion and delivery of alternate autologous adult stem cells like oral mucosal epithelium [3-5], conjunctival epithelium [6,7] and hair follicle derived stem cells [8] are now being looked into as promising approach for
LSCD treatment. There are scanty reports on the use of such alternate cell sources and the clinical outcomes are often less satisfactory $[9,10]$. The success of treatment methodology involving ex vivo expansion and transplantation largely depends upon the stabilization of physiologic conditions of the eye and in providing a niche for the restoration of stem cell milieu and graft survival.

It is well established that epithelial-mesenchymal interactions of eye plays a major role in wound healing, development and maintenance of LSCs. Mesenchymal stem cells (MSC) due to its multifunctional properties like immunomodulatory and anti-inflammatory functions [11], multipotency [12,13] and relative ease of expansion in culture represents a readily accessible source of adult cells for tissue repair and reconstruction. Moreover, promising results has been obtained in recent studies with MSC for treating corneal chemical burns [14-17]. In this context, it would be very much appreciable to transdifferentiate MSC to corneal epithelial like cells prior to transplantation, which could be used as an alternate autologous cell source in treatments involving bilateral limbal deficiency. This study was aimed in transdifferentiating MSC to corneal epithelial like cells in vitro by simulating corneo-limbal niche using extracellular matrix (ECM) and conditioned media.

Correspondence to: T.V Kumary, Scientist -G, Tissue Culture Lab, Biomedical Technology Wing, Sree Chitra Thirunal Institute for Medical Sciences and Technology, Poojappura, Trivandrum, Kerala, India, Tel: +91 471 2520271; Fax: +91 471 2341814; E-mail: tvkumary@yahoo.com; tvkumari@sctimst.ac.in

Key words: mesenchymal stem cells, limbal fibroblasts, stem cell - microenvironment interactions, transdifferentiation, cellular therapy

Received: April 03, 2017; Accepted: May 05, 2017; Published: May 08, 2017 


\section{Materials and methods}

Isolation and maintenance of rabbit bone marrow mesenchymal stem cells

MSC were isolated from the femurs of two-year-old New Zealand White rabbits by direct plating method as previously described [18]. The study was approved by the Institute Animal Ethics Committee (IAEC) of Sree Chitra Thirunal Institute of Medical Sciences and Technology (SCTIMST). Briefly, the femur was collected in phosphate buffered saline (PBS) containing $1 \mathrm{X}$ antibiotic (penicillin /streptomycin, PAA laboratories, Germany). The bone was cleaned and bone marrow was flushed out. The cell suspension was mixed, centrifuged at $600 \mathrm{~g}$ for 10 min (Eppendorf, Germany) and was resuspended in Dulbecco's Modified Eagle Medium (DMEM) (Himedia, India) containing 10\% fetal bovine serum (FBS) (Lonza, USA). Isolated cells were cultured on $25 \mathrm{~cm}^{2}$ culture flask (Cell Star, Germany) and maintained at $37^{\circ} \mathrm{C}, 5 \%$ $\mathrm{CO}_{2}, 95 \%$ humidity in a $\mathrm{CO}_{2}$ incubator (Sanyo, Japan). Medium change was given thrice a week.

\section{Proliferation of rabbit mesenchymal stem cells}

Proliferation of MSC in three different commercially available media: DMEM, DMEM low glucose (DMEM LG) and $\alpha$-minimum essential medium (a MEM) (Invitrogen, USA) were analyzed. After attaining confluence, MSC were seeded at a density of $2 \times 10^{3}$ cells $/ \mathrm{cm}^{2}$ on 12 well plate (Cell Star, Germany) and were cultured in the respective medium for $24 \mathrm{~h}$ and $48 \mathrm{~h}$. At the end of culture period, proliferation of MSC was determined by MTT [(3-(4,5- Dimethylthiazol-2-yl)-2,5diphenyltetrazolium bromide] assay. Cells were treated with MTT (Sigma Aldrich, Germany) $(0.5 \mathrm{mg} / \mathrm{ml})$ for $4 \mathrm{~h}$ to allow the formation of formazan crystals, followed by their solubilization with isopropanol (MERCK, USA). Supernatant was transferred to a 96 well plate and the absorbance was read using a spectrophotometer (Biotek Powerwave XS, USA) at $570 \mathrm{~nm}$. Optimum medium was selected for further experiments and MSC cultured under this condition was analyzed by immunocytochemistry and flow cytometry for the expression of mesenchymal lineage specific markers (CD105, vimentin, ABCG2, CD90 and CD29).

\section{Isolation and culture of rabbit limbal fibroblasts}

From the harvested eyes, the limbus was excised and washed twice in PBS containing $1 \mathrm{X}$ antibiotic and de-epithelialized by treating with $2 \mathrm{mg} / \mathrm{ml}$ dispase II (Roche, USA) for 20 min followed by mechanical debridement. Stromal layer was excised off from de-epithelialized limbal tissue and was incubated for $2 \mathrm{~h}$ in collagenase - type I ( $1 \mathrm{mg} / \mathrm{ml}$ ) (Sigma Aldrich, Germany), at $37^{\circ} \mathrm{C}$ in a $\mathrm{CO}_{2}$ incubator. The resultant digest was centrifuged and the pellet was resuspended in DMEM (Invitrogen, USA) containing 10\% FBS. The cells were cultured in $60 \mathrm{~mm}$ dishes (Cell Star, Germany) for 21 days and the cell growth were monitored using phase contrast microscope (Leica, Germany). Cultured limbal fibroblasts (LF) were characterized by immunocytochemistry and flow cytometry for the expression of fibroblast lineage specific markers Secreted Protein Acidic and Rich in Cysteine (SPARC), vimentin and CD90.

\section{Transdifferentiation of MSC to corneal lineage}

MSCs were differentiated to corneal lineage by simulating the corneo-limbal niche factors using extracellular matrix (ECM) coated plates/dishes/coverslips (CVs) and limbal fibroblast conditioned medium (CM).

\section{Coating of extracellular matrix components}

Type I collagen (Nutacon, Netherlands) was used as the ECM component for transdifferentiation studies. Collagen was coated by adding collagen solution $(1.5 \mathrm{mg} / \mathrm{ml})$ to dish and spreading uniformly. Plates were then incubated for $1 \mathrm{~h}$ at $37^{\circ} \mathrm{C}$ and were gently washed with PBS before use.

\section{Preparation of conditioned medium}

Conditioned medium was prepared using the spent medium of the LF primary cultures. The spent medium was collected on every alternate day from LF cultures, centrifuged at $3000 \mathrm{rpm}$ for $15 \mathrm{~min}$ to remove cell debris, filtered using 0.22 micron syringe filter, aliquoted and stored at $-80^{\circ} \mathrm{C}$ until use.

\section{Simulation of niche factors for inducing transdifferentiation of MSC}

To study the role of niche factors in the differentiation of MSC, three different culture systems were selected $\left(\mathrm{CS}_{e c m}, \mathrm{CS}_{e c m+c m}\right.$ and $\left.\mathrm{CS}_{c m}\right)$. A combination of ECM and CM was used to formulate this culture system $\left[\left(\mathrm{CS}_{e c m}\right.\right.$ : ECM coating alone), $\left(\mathrm{CS}_{e c m+c m}\right.$ : ECM coating $\left.+\mathrm{CM}\right)$, (CS : $\mathrm{CM}$ alone)]. MSC were cultured in this culture system for 7 days and the transdifferentiation to corneal epithelial lineage was analyzed by immunocytochemistry and flow cytometry for the expression of ABCG2, CD29 and cytokeratins 3/12. RT-PCR was also done for evaluating CK12 expression.

\section{Immunocytochemistry}

MSC, LF and transdifferentiated MSC were characterized by immunocytochemistry. Cells cultured on CVs were fixed using $4 \%$ buffered paraformaldehyde (30 $\mathrm{min}$ ) and permeabilized with $0.1 \%$ Triton X solution (Sigma Aldrich, Germany). Nonspecific binding of antibodies was blocked by incubating cells in $1 \%$ bovine serum albumin (BSA) for $10 \mathrm{~min}$. Cells were then rinsed and incubated with primary antibody (1:100) (table-1) for $1 \mathrm{~h}$ and was followed by incubation with goat anti mouse IgG-FITC (Sigma Aldrich, Germany) (1:100) for $1 \mathrm{~h}$ in dark. Cells were rinsed and counter stained with propidium Iodide (PI) (Sigma Aldrich, Germany) $(0.05 \mu \mathrm{g} / \mathrm{ml})$ for $2 \mathrm{~min}$. CVs were then mounted with fluorescent mounting medium (Dako Cytomation, USA) and was analyzed by Laser Scanning Confocal Microscope (LSM510 META, Carl Zeiss, Germany) using Argon and HeNe lasers. Fluorescence emission was detected using filter of FITC and PI.

\section{Flow cytometry analysis}

MSC, LF and trans differentiated MSC were further characterized by flow cytometry analysis. Cells were harvested by trypsinization and made into single cell suspension by passing through a cell strainer of pore size $70 \mu \mathrm{m}$ (BD falcon, USA). The cell suspension was pelleted by centrifuging at $600 \mathrm{~g}$ for $30 \mathrm{~min}$, fixed in $4 \%$ buffered paraformaldehyde, repelleted and permeabilized using $0.1 \%$ Triton X. The nonspecific binding sites were blocked by incubating with $1 \%$ BSA and cells were incubated with primary antibody (1:100) (Table 1) for $45 \mathrm{~min}$ at room temperature. Primary antibody was replaced with appropriate secondary antibody (1:100) and incubated further for $45 \mathrm{~min}$. The cells were then pelletted and resuspended in PBS for analysis using a flow cytometer (FACS Aria, BD USA). The results were analyzed by BD FACS Diva software.

\section{RT-PCR analysis}

Transdifferentiated MSCs were characterized by RT-PCR as described previously [19]. RNA was collected from cells on $3^{\text {rd }}$ and $7^{\text {th }}$ 
Table 1. Antibodies used for immunostaining / flow cytometry.

\begin{tabular}{|l|l|l|}
\hline \multicolumn{1}{|c|}{ Primary antibody } & Characteristic protein & \multicolumn{1}{c|}{ Company } \\
\hline $\begin{array}{l}\text { Monoclonal mouse anti cow } \\
\text { vimentin clone (Vim 3B4) }\end{array}$ & $\begin{array}{l}\text { Intermediate filaments, } \\
\text { vimentin }\end{array}$ & Dako Cytomation, USA \\
\hline $\begin{array}{l}\text { Mouse anti human integrin } \beta 1 \text { four } \\
\text { (CD29) }\end{array}$ & Integrin & Millipore, USA \\
\hline FITC mouse anti human CD90 & Thymine 1 & BD Pharmingen, USA \\
\hline $\begin{array}{l}\text { ABCG2 (BRCP1) purified mouse } \\
\text { anti human monoclonal antibody }\end{array}$ & $\begin{array}{l}\text { Transmembrane } \\
\text { protein }\end{array}$ & BD Pharmingen, USA \\
\hline $\begin{array}{l}\text { Endoglin rat monoclonal IgG } \\
\text { CD105 }\end{array}$ & TGF $\beta$ receptor & $\begin{array}{l}\text { Santacruz Biotechnology, } \\
\text { USA }\end{array}$ \\
\hline Osteonectin /SPARC & $\begin{array}{l}\text { Bovine bone } \\
\text { osteonectin }\end{array}$ & QED bioscience, USA \\
\hline $\begin{array}{l}\text { Monoclonal mouse anti human } \\
\text { cytokeratin clone AE1/AE3, }\end{array}$ & cytoskeleton & Dako cytomation, USA \\
\hline
\end{tabular}

All antibodies were used in 1:100 dilutions.

day by treating with TRIsoln reagent (Bangalore Genei, India). RNA was isolated, precipitated and resuspended in nuclease free water. Complementary DNA (cDNA) was synthesized from $1.2 \mu \mathrm{g}$ RNA using M-MuLV RT-PCR kit (Bangalore Genei, India) in a thermocycler (Eppendorf AG, Germany). PCR was then performed using Genei Red Dye PCR Master Mix (Bangalore Genei, India) according to manufacturer's protocol. PCR amplification was performed with specific primer pairs for different markers [20], as given in table 2 . The cyclic conditions were set for 35 cycles, each with denaturation at $94^{\circ} \mathrm{C}$ for 30 s, specific annealing temperature (Table 2) for 30 s and extension at $72^{\circ} \mathrm{C}$ for $1 \mathrm{~min}$. The PCR products were subjected to electrophoresis in $2 \%$ agarose gel containing $0.4 \mu \mathrm{g}$ ethidium bromide (Bangalore Genei, India) and was imaged using a Phosphor Imager (Fujifilm FLA 5100, Japan).

\section{Statistical analysis}

Data obtained from three independent experiments were expressed as mean \pm standard deviation and was used for the analysis. Statistical significance between groups was analyzed using student's $t$ test. For all analysis, differences were considered significant when $\mathrm{p}<0.05$.

\section{Results}

\section{Culture and characterization of MSC}

MSC were isolated and cultured based on their ability to adhere to plastic cell culture plates. These adherent cells were spindle-shaped in morphology and proliferated as colonies. Optimization of culture conditions for in vitro expansion and maintenance of MSC was done by assessing their proliferation by MTT assay. Among the three media screened, a MEM was found to be supporting more proliferation compared to DMEM-LG and DMEM $(\mathrm{p}<0.001)$ (Figure 1). Hence a MEM was selected for culturing MSC for further experiments.

The immunocytochemistry of MSC cultured in a MEM showed expression of CD105, ABCG2 and vimentin, but was negative for CD90 (Figure 2a-d). These findings were further confirmed by flow cytometry. Flow cytometry analysis showed cultured MSC were positive for the expression of vimentin $(99 \% \pm 0.44 \%)$, CD105 (99\% \pm $0.54 \%)$ and ABCG2 $(99 \% \pm 0.63 \%)$. The cultured MSC showed reduced expression of CD29 $(75 \% \pm 5.63 \%)$ and negative expression of CD90 $(1 \% \pm 0.11 \%)$ (Figure $2 \mathrm{e}-\mathrm{j})$.

\section{Culture and characterization of limbal fibroblast}

LF isolated from de-epithelialized limbal tissue cultured in DMEM were characterized for limbal fibroblasts specific markers (SPARC, vimentin and CD90) by immunocytochemistry and flow cytometry.
The cultured cells showed typical spindle morphology of fibroblasts with extensive proliferation (Figure 3a-c). Immunocytochemistry showed their cytoplasmic expression of SPARC and vimentin, but were negative for CD90 expression (Figure 3d-f). Further quantitative analysis by flow cytometry reconfirmed the immunocytochemistry data (vimentin $=98 \%$, SPARC $=99 \%$ and CD90 $=0.3 \%)($ Figure $3 g-j)$. These results confirmed that the cultured cells from de-epithelialized limbal tissue were LF.

\section{Transdifferentiation of MSC to corneal lineage}

The role of limbal niche factors [ECM and LF released factors $(\mathrm{CM})$ ] in inducing transdifferentiation of MSC to corneal lineage was evaluated using three culture systems $\left(\mathrm{CS}_{e \mathrm{~cm}}, \mathrm{CS}_{\text {ecm+cm }}\right.$ and $\left.\mathrm{CS}_{c \mathrm{~m}}\right)$ by monitoring expression of corneal epithelial markers (CK3/12) and stem cells markers (ABCG2 and CD29) on $3^{\text {rd }}$ and $7^{\text {th }}$ day of culture. Immunocytochemistry showed the expression of ABCG2 by cells cultured in $\mathrm{CS}_{\text {ecm, }}$ but were negative for $\mathrm{CK} 3 / 12$ on both $3^{\text {rd }}$ and $7^{\text {th }}$ day (figure $4 \mathrm{a}-\mathrm{d}$ ). In $\mathrm{CS}_{\text {ecm+cm }}$ and $\mathrm{CS}_{\mathrm{cm}}$, cells expressed both ABCG2 and CK3/12 (figure 4e-1). Further analysis of cellular gene expression profile for CK12 showed their negative expression in $\mathrm{CS}_{e c m}$ but was positive in $\mathrm{CS}_{e c m+c m}$ and $\mathrm{CS}_{c m}$, on both $3^{\text {rd }}$ and $7^{\text {th }}$ day (Figure $4 \mathrm{~m}$ ). This result was further evaluated and quantified by flow cytometry for $\mathrm{CS}_{\text {ecm }}$ (Figure 5), $\mathrm{CS}_{e c m+c m}$ (Figure 6), and $\mathrm{CS}_{c m}$, (Figure 7). The quantitative values obtained for the expression of these markers in three culture systems is summarized in table 3 . Flow cytometry data reconfirmed the findings obtained by immunocytochemistry and RT-PCR.

\section{Discussion}

Corneal disorders are the fourth leading cause of blindness and a major problem in ophthalmology [21] This emphasizes the need for continual search for improved treatment regimes. Corneal integrity and function is dependent on the homeostasis of the outermost corneal layer, the corneal epithelium. Corneal epithelium is replenished at definite intervals by LSCs located in the basal layer of the limbus in

Table 2. Primer sequence, annealing temperature and product length.

\begin{tabular}{|c|c|c|c|}
\hline Gene & Primer sequence & $\begin{array}{c}\text { Annealing } \\
\text { Temperature }\left({ }^{\circ} \mathbf{C}\right)\end{array}$ & $\begin{array}{c}\text { Product length } \\
\text { (bp) }\end{array}$ \\
\hline B Actin & $\begin{array}{c}\text { FP-ATCGTGATGGACTCCGGCGA } \\
\text { RP-AGGAAGGAGGGCTGGAACAG }\end{array}$ & 52 & 350 \\
\hline CK 3 & $\begin{array}{c}\text { FP-GGCAGAGATCGAGGGTCTC } \\
\text { RP-GTCATCCTTCGCCTGCTGTAG }\end{array}$ & 64 & 145 \\
\hline CK 12 & $\begin{array}{c}\text { FP-CATGAAGAAGAACCACGAGGATG } \\
\text { RP-TCTGCTCAGCGATGGTTTCA }\end{array}$ & 63 & 150 \\
\hline
\end{tabular}

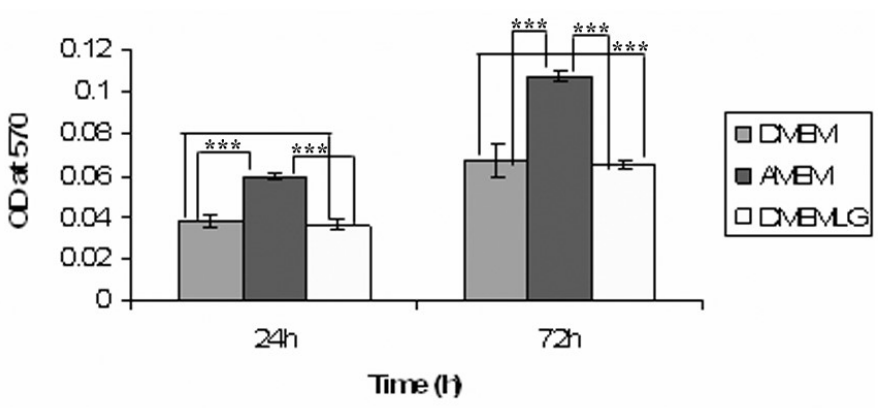

Figure 1. Proliferation of mesenchymal stem cells. MTT assay profile of mesenchymal stem cells cultured in different media after $24 \mathrm{~h}$ and $72 \mathrm{~h}$. Data expressed as mean \pm SD of three different experiments. Cellular activity of MSC cultured in $\alpha$-minimum essential medium ( $\alpha$ MEM) was compared with that of Dulbecco's Modified Eagle Medium (DMEM) and Dulbecco's Modified Eagle Medium-low glucose (DMEM LG) and significant differences $(\mathrm{p}<0.05)$ are denoted by $* *$. 

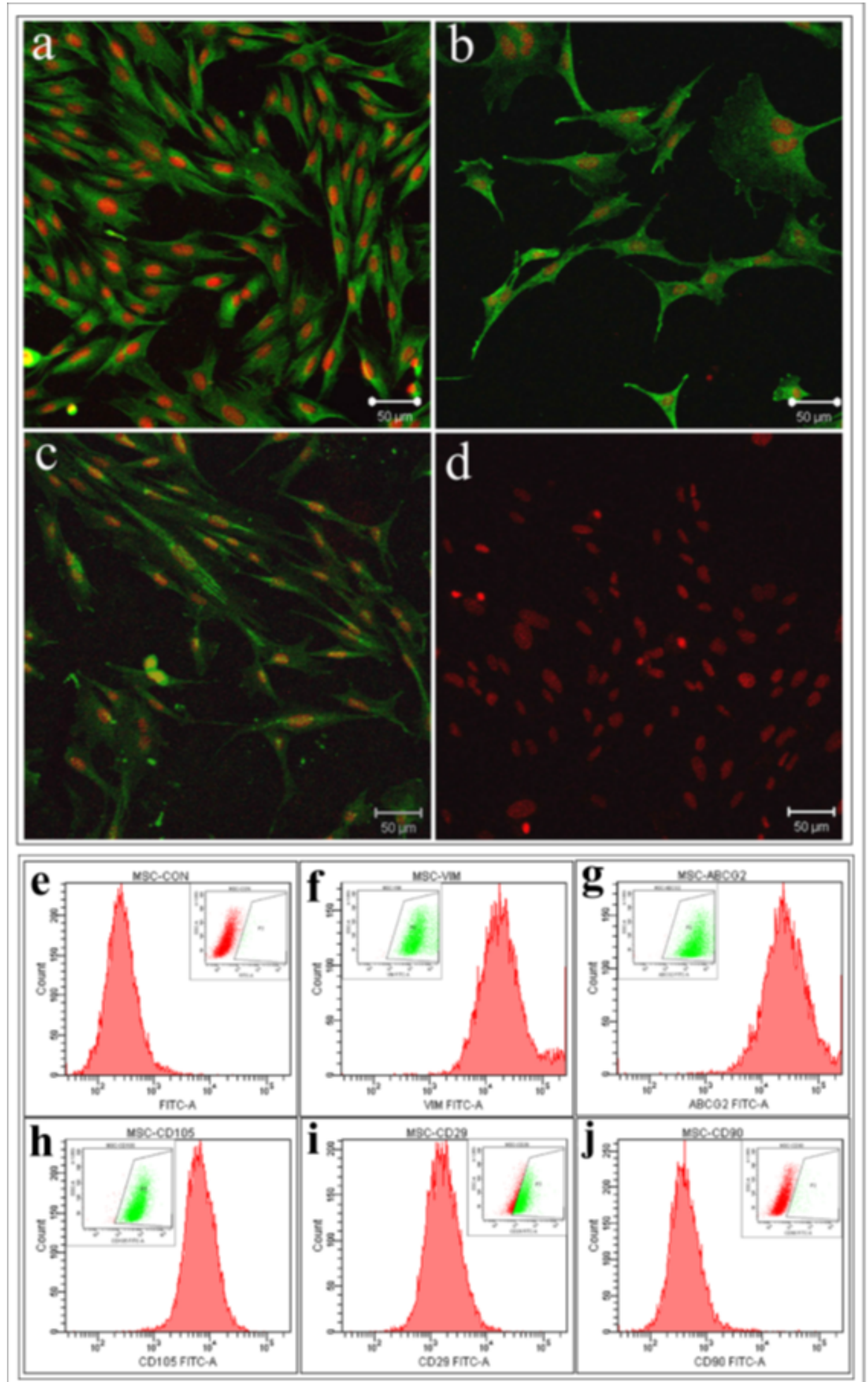

Figure 2. Characterization of mesenchymal stem cells: Representative confocal image showing the expression of (a) Vimentin, (b) ABCG2, (c) CD105 and (d) negative expression of CD90 in rabbit bone marrow mesenchymal stem cells. Scale bar denotes $50 \mu \mathrm{m}$. Flow cytometry analysis of rabbit bone marrow mesenchymal stem cells showing the expression of (f) vimentin (g) ABCG2 (h) CD105 (i) CD29 and (j) negative expression of CD90. The inset image denotes the gated population and (e) represents the isotype control. 

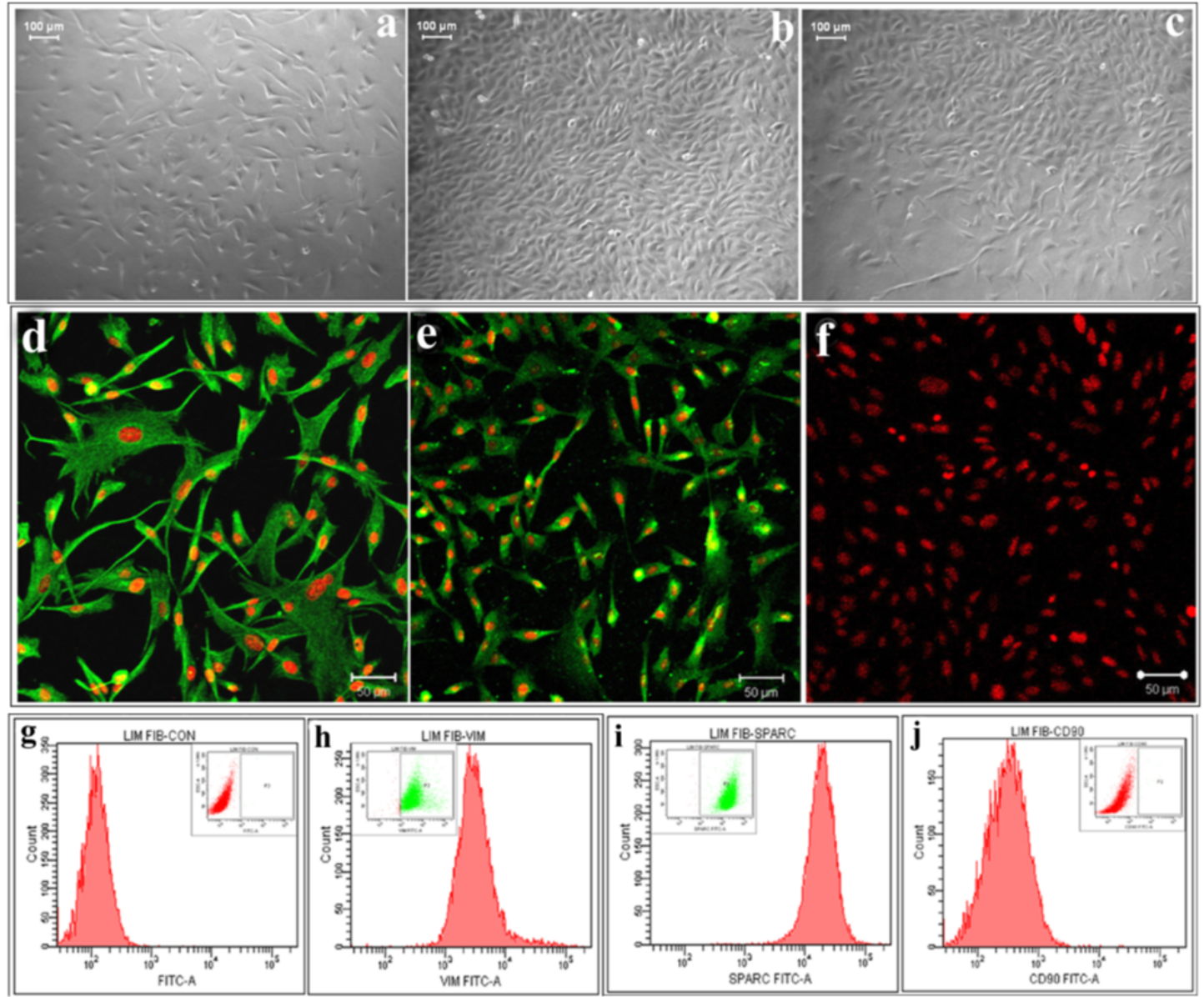

Figure 3. Characterization of LF: phase contrast image of LF in primary culture showing elongated fibroblast morphology on (a) $4^{\text {th }}$ day, (b) $10^{\text {th }}$ day and (c) after passaging

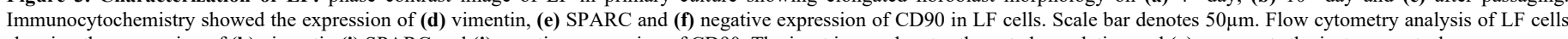
showing the expression of (h) vimentin (i) SPARC and (j) negative expression of CD90. The inset image denotes the gated population and (g) represents the isotype control.

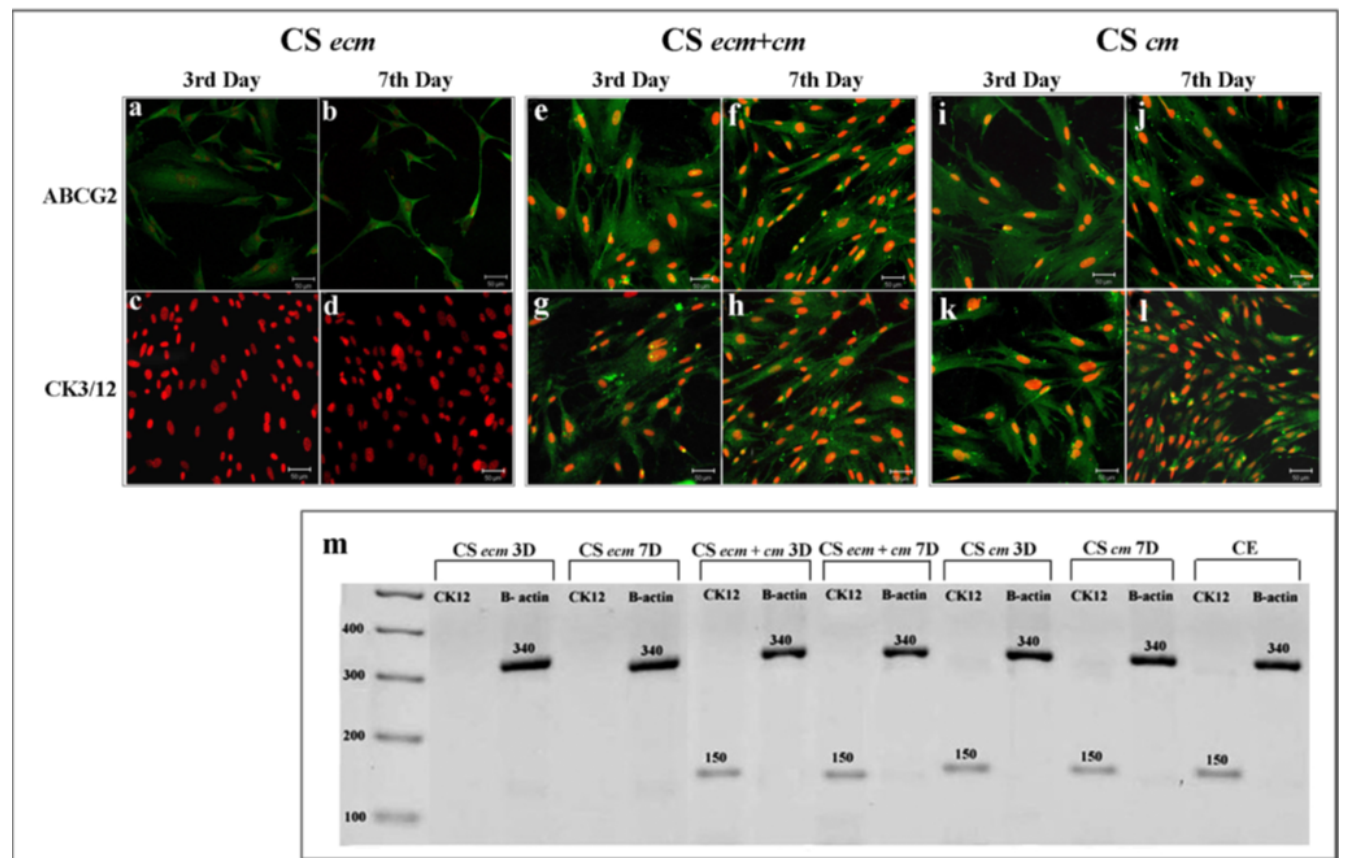

Figure 4. Transdiffrentiation of MSC in culture systems. Immunocytochemistry of cells in $\mathrm{CS}_{\mathrm{ccm}}(\mathbf{a}-\mathbf{d}), \mathrm{CS}_{\mathrm{ecm}+\mathrm{cm}}(\mathrm{e}-\mathbf{h})$ and $\mathrm{CS}_{\mathrm{cm}}(\mathbf{i}-\mathrm{l})$ on $3^{\text {rd }}$ and $7^{\text {th }}$ day showing the expression of $\mathrm{ABCG} 2$

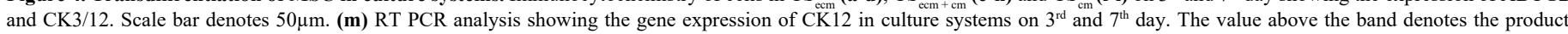

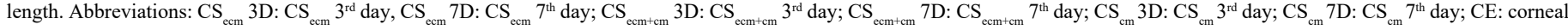
epithelium; CK12: cytokeratin 12; B actin: $\beta$ actin. 

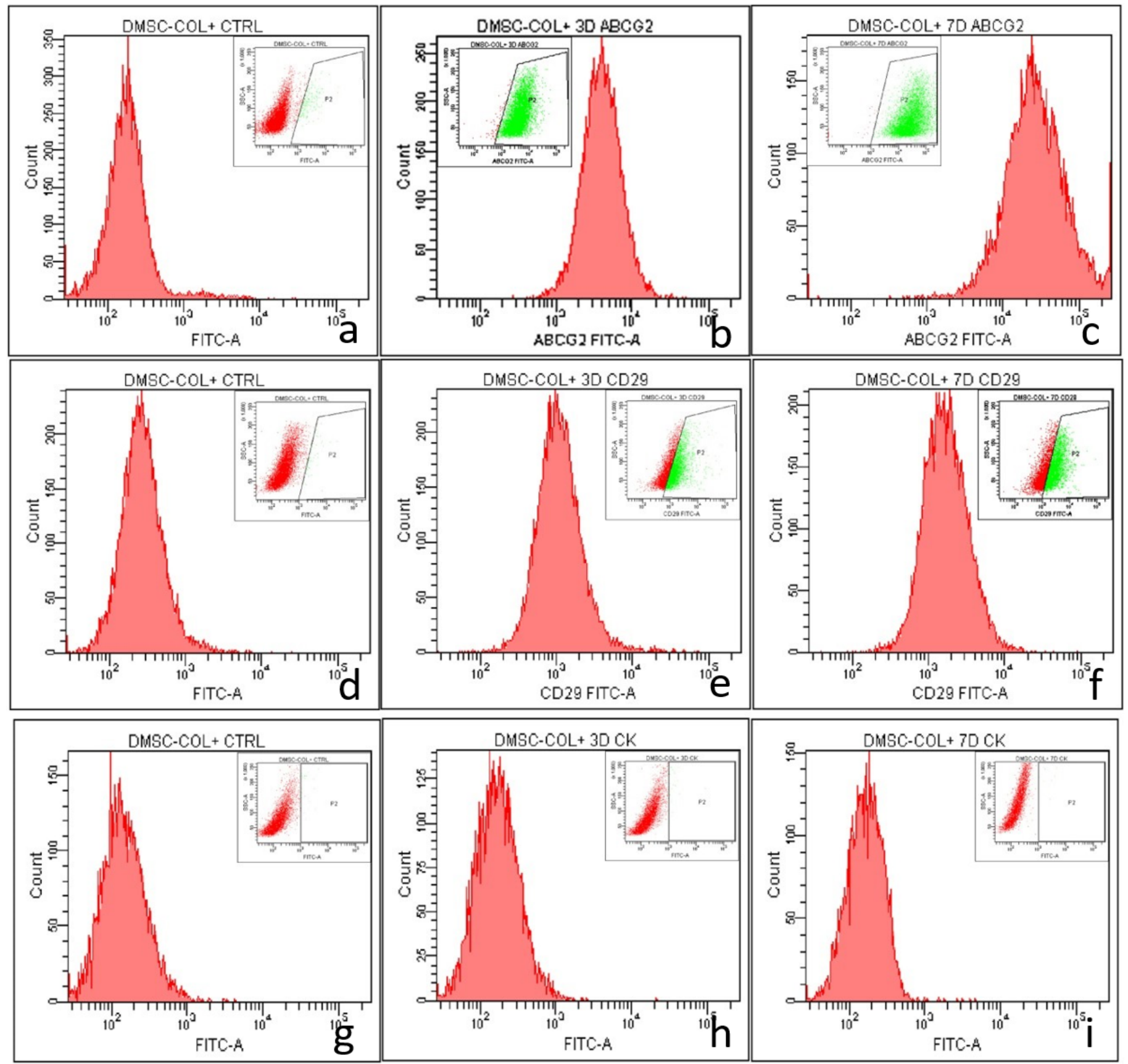

Figure 5. Flow cytometry analysis of MSC in $\mathrm{CS}_{\text {ecm }}$ showing the expression of (a, b, c) ABCG2 (a) control (b) 3 day (c) 7 day, (d, e, f) CD29 (d) control (e) 3 day (f) 7 day and (g, h, i) CK3/12 (g) control (h) 3 day (i) 7 day. The inset image denotes the gated population.

close proximity to limbal niche [1,2], which plays an important role in the maintenance of stem cells [22]. Any damage or dysfunction of this limbal niche can affect the LSC populations and can severely compromise ocular surface integrity and vision [23].

Selection of treatment regime depends on the extent of damage to the limbal niche and the LSCs. In severe cases a cell transplantation therapy is necessary where the host stem cells are inefficient to revive the corneal layer. In order to replenish the stem cell population in eye, it is always desirable to use autologous cells for transplantation since it avoids the risk of immune rejection and the need for immunosuppression. However in bilateral LSCD condition, transplantation of allogenic stem cells or ex vivo expanded cells are employed due to lack of autologous LSCs cell sources. Allograft transplantation requires long-term immunosuppression that involves high risks of systemic complications. A major strategy for bilateral LSCD treatment involves the ex vivo expansion, differentiation and delivery of alternate autologous stem cells viz delivery systems like amniotic membranes and fibrin glue [24]. Identifying the best non-ocular cell source is now well attempted in the field of ophthalmology and bone marrow stem cell is one prominent group in that research stream. Bone marrow contains hematopoietic and mesodermal precursors. MSC are of intense therapeutic interest because of its multipotency, ready availability, relative ease of expansion in culture and low immunogenicity [25-27]. Recently, there have 

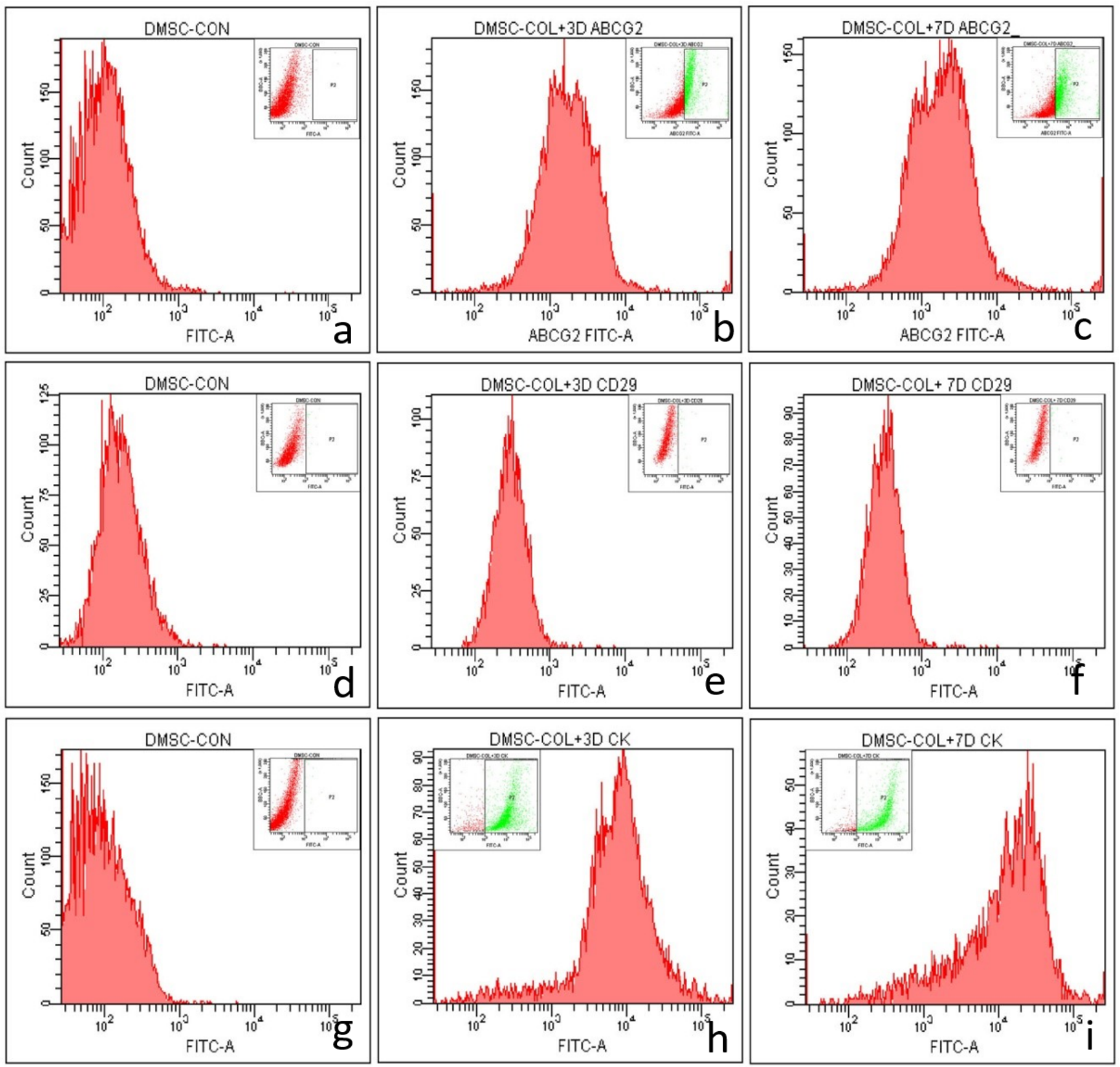

Figure 6. Flow cytometry analysis of MSC in $\mathrm{CS}_{\text {ecm+cm }}$ showing the expression of (a, b, c) ABCG2 (a) control (b) 3 day (c) 7 day, (d, e, f) CD29 (d) control (e) 3 day (f) 7 day and (g, h, i) CK3/12 (g) control (h) 3 day (i) 7 day. The inset image denotes the gated population.

also been significant advances in the use of autologous mesenchymal stem cells to regenerate human tissues [28,29]. It has been reported that MSC express markers pertaining to corneal epithelial stem cells [30-33] and can be induced to differentiate to epithelial like cells both in vitro and in vivo [33-36]. A critical factor in mesenchymal stem cell biology is to propagate cells with suitable stem cell characteristics, multipotency and high proliferative potential for its use in various biomedical applications. Under in vitro conditions, culture media plays a major role in growth, multiplication and maintenance of stemness of cells. Thus selection of optimal medium for culture and expansion of stem cells is crucial. In this study MSC were isolated and maintained in different media formulations and cells cultured in a MEM showed more proliferation and maintenance potential of stem cells similar to previous reports [37]. Although no unique marker is known for MSC, their cell-surface antigen profile has been well explored. According to previous reports, MSC express markers such as ABCG2 [38], CD105 [39], vimentin [40] and CD90 [41]. The expression of ABCG2 was found to be localized in the cell membrane as well as in cytoplasm, as reported earlier [42]. Characteristic cytoskeletal expression of vimentin illustrated the filamentous nature and confirmed the significant role of vimentin in supporting and anchoring. It has been reported that great variation exists in the expression of $\mathrm{CD} 90$ which are reported to be 

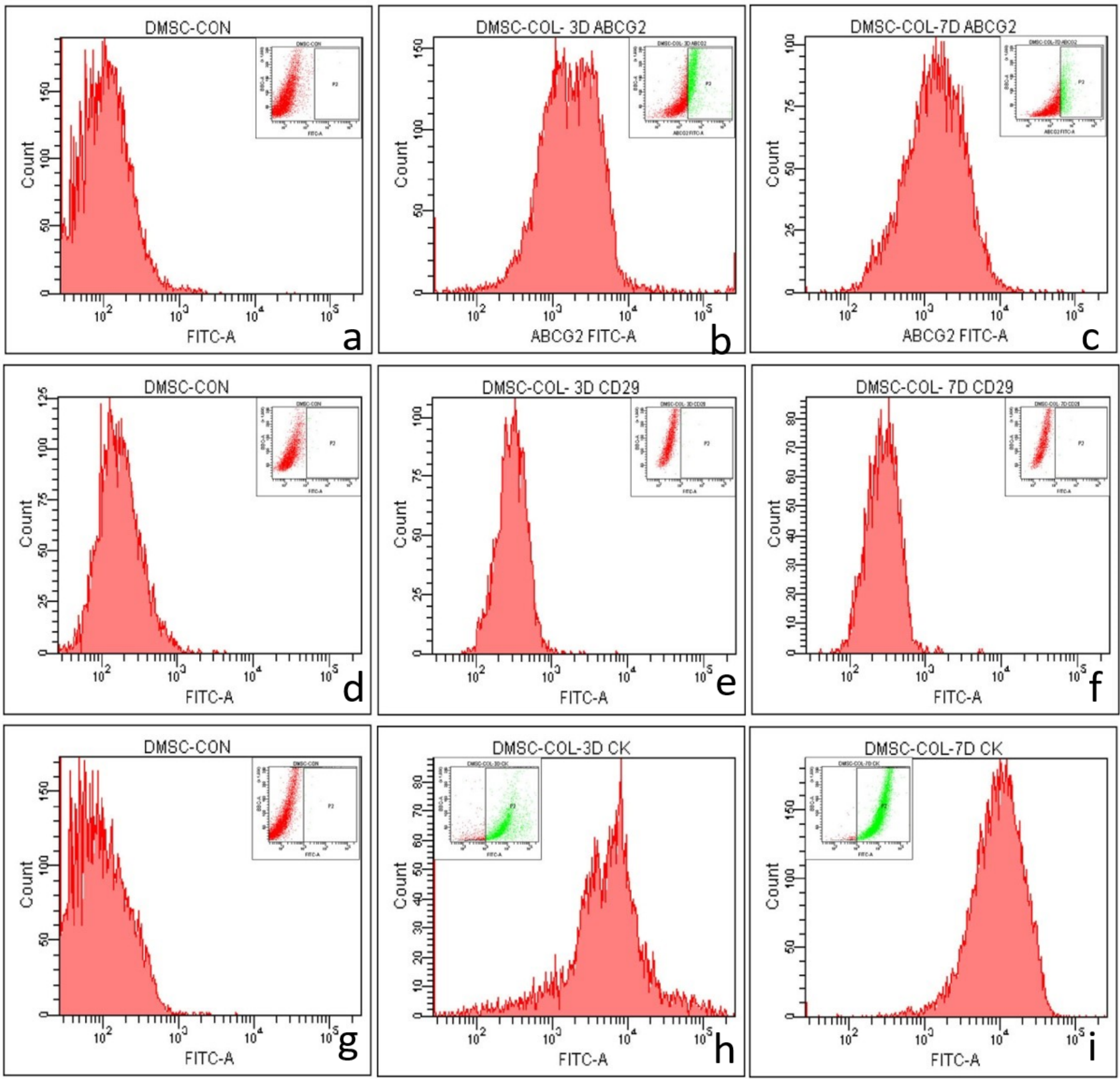

Figure 7. Flow cytometry analysis of MSC in $\mathrm{CS}_{\mathrm{cm}}$ showing the expression of (a, b, c) ABCG2 (a) control (b) 3 day (c) 7 day, (d, e, f) $\mathrm{CD} 29$ (d) control (e) 3 day (f) 7 day and (g, h, i) CK3/12 (g) control (h) 3 day (i) 7 day. The inset image denotes the gated population.

expressed mostly by mesenchymal stromal cells [43]. The expression of CD90 was found to be negative, which we presume may be due to different stage of cell commitment and culturing conditions [37]. The immune reactivity obtained against ABCG2, CD105 and vimentin as well as the negative reaction for CD90 concord with previously reported findings [37].

Fibroblast like cells in the limbal stroma with self-renewal property and multipotency similar to MSC have been reported [44]. Here we describe the isolation and maintenance of rabbit LF with spindle shaped morphology and high proliferative potential. In order to determine the phenotype of isolated cells from limbal stroma of rabbits, the cells were characterized by markers as reported elsewhere $[8,37,43]$. SPARC has been suggested as one of the markers expressed only by LF cells which have a functional role in maintenance of corneal homeostasis [43]. Immunocytochemical analysis of LF cultures showed the cytoplasmic, filamentous expression of vimentin suggesting its mesodermal origin. The expression of SPARC in the cytoplasm of cells confirmed that the isolated cells were LF. The results obtained in our study correlated well with previous reports [43]. However, negative expression of CD90 was noted for rabbit LF, which were contradictory to the findings of Ahmad et al in human fibroblasts [42]. The data obtained from our study suggest that the rabbit LF are negative for the expression of $\mathrm{CD} 90$ and hence can be regarded as a negative marker for the characterization of such cells in future. 
Table 3. Expression levels of various antigens in different culture systems.

\begin{tabular}{|c|c|c|c|c|c|c|}
\hline \multirow[t]{2}{*}{ Culture System } & \multicolumn{2}{|c|}{ CK3/12 } & \multicolumn{2}{|c|}{ ABCG2 } & \multicolumn{2}{|c|}{ CD29 } \\
\hline & $3^{\text {rd }}$ Day & $7^{\text {th }}$ Day & $3^{\text {rd }}$ Day & $7^{\text {th }}$ Day & $3^{\text {rd }}$ Day & $7^{\text {th }}$ Day \\
\hline $\mathrm{CS}_{\mathrm{ecm}}$ & $0.5 \pm 0.01 \%$ & $0.2 \pm 0.11 \%$ & $97 \pm 1.65 \%$ & $98 \pm 1.22 \%$ & $53 \pm 2.33 \%$ & $53 \pm 3.22 \%$ \\
\hline $\mathrm{CS}_{\mathrm{ecm}+\mathrm{cm}}$ & $86 \pm 2.31 \%$ & $86 \pm 3.44 \%$ & $34 \pm 6.33 \%$ & $39 \pm 2.66 \%$ & $1 \pm 0.87 \%$ & $1 \pm 0.44 \%$ \\
\hline $\mathrm{CS}_{\mathrm{cm}}$ & $84 \pm 3.21 \%$ & $88 \pm 4.11 \%$ & $36 \pm 2.33 \%$ & $21 \pm 3.22 \%$ & $0.3 \pm 0.11 \%$ & $0.4 \pm 0.22 \%$ \\
\hline
\end{tabular}

Percentage of cells positive for $\mathrm{CK} 3 / 12, \mathrm{ABCG} 2$ and $\mathrm{CD} 29$ in culture systems $\left(\mathrm{CS}_{\mathrm{ecm},}, \mathrm{CS}_{\mathrm{ecm}+\mathrm{cm}}, \mathrm{CS}_{\mathrm{cm}}\right)$ revealed by flow cytometry analysis.

The stem cell maintenance and function are regulated by various intrinsic and extrinsic factors provided by a unique local microenvironment or niche. The limbal stem cells and their progeny that reside within small clusters in the basal epithelium in close spatial relationship with specific basement membrane and matrix components [44-48] as well as with stromal fibroblasts provides increased levels of growth and survival factors $[41,49]$. Previous reports demonstrate that it is possible to differentiate stem cells to corneal epithelial cells by simulating the limbal niche either by co culture, or in the presence of collagen and limbal fibroblast CM [50]. In order to replicate such culture conditions, in vitro transwell culture systems have been implemented to make use of secretory factors to aid in differentiation [51]. In our study, 3 different culture systems were formulated based on 2 parameters - ECM and conditioned medium. The corneal matrix is known to contain collagen-I [52] [53] and hence was used as one of the parameters. Expression levels of $\mathrm{CK} 3 / 12$ were used for evaluating differentiation into corneal epithelial phenotype. Results showed that collagen-I alone had no role in regulating cell differentiation, but favored the maintenance of stem cells as indicated by increased expression of ABCG2 and CD29. In $\mathrm{CS}_{\text {ecm+cm }}$, the number of cells expressing CK3/12 was found to be increased with a concomitant reduction in the expression of stem cell markers. The $\mathrm{CS}_{\mathrm{cm}}$ alone was also found to aid in differentiation and expression of corneal epithelial phenotype. We presume that the released factors produced by limbal stromal cells might have promoted MSC to differentiate into the corneal epithelium in vitro. The current findings shows that secretory factors by LF can induce transdifferentiation of bone marrow derived stem cells to corneal epithelial-like cells, as indicated by CK12 expression. The precise molecular mechanisms of differentiated reprogramming remains to be determined and further substantiation are required in in vivo models of LSCD. This study demonstrated that rabbit MSC could be induced into corneal epithelial-like cells in vitro, providing a new source of cells for the treatment of corneal disorders.

\section{Conclusion}

Mesenchymal stem cells could be transdifferentiated into corneal epithelial-like cells in vitro by simulating corneo-limbal niche. Transdifferentiating mesenchymal stem cells to corneal epithelial like cells will provide a useful, autologous source of adult stem cells in therapeutic approaches for patients suffering from bilateral limbal stem cell deficiency.

\section{Acknowledgement}

The authors thank Sree Chitra Tirunal Institute for Medical Sciences and Technology (SCTIMST) for the facilities and Department of Biotechnology, Government of India for financial support.

\section{References}

1. Arpitha P, Prajna NV, Srinivasan M, Muthukkaruppan V (2008) A subset of human limbal epithelial cells with greater nucleus-to-cytoplasm ratio expressing high levels of p63 possesses slow-cycling property. Cornea 27:1164-1170.

2. Limb GA, Daniels JT (2008) Ocular regeneration by stem cells: present status and future prospects. Br Med Bull 85: 47-61.[Crossref]
3. Resnikoff S, Keys TU (2012) Future trends in global blindness. Indian J Ophthalmol60: 387-395.[Crossref]

4. Nishida K, Yamato M, Hayashida Y, Watanabe K, Yamamoto K, et al. (2004) Corneal reconstruction with tissue-engineered cell sheets composed of autologous oral mucosal epithelium. N Engl J Med 351:1187-1196.

5. Madhira SL, Vemuganti G, Bhaduri A, Gaddipati S, Sangwan VS, et al. (2008) Culture and characterization of oral mucosal epithelial cells on human amniotic membrane for ocular surface reconstruction. Mol Vis 14:189-196.

6. Ono K, Yokoo S, Mimura T, Usui T, Miyata K, et al. (2007) Autologous transplantation of conjunctival epithelial cells cultured on amniotic membrane in a rabbit model. $\mathrm{Mol}$ Vis 13:1138-1143.

7. Tanioka H, Kawasaki S, Yamasaki K, Ang LP, Koizumi N, et al. (2006) Establishment of a cultivated human conjunctival epithelium as an alternative tissue source for autologous corneal epithelial transplantation. Invest Ophthalmol Vis Sci 47:3820-3827.

8. Blazejewska EA, Schlotzer-Schrehardt U, Zenkel M, Bachmann B, Chankiewitz E, et al. (2009) Corneal limbal microenvironment can induce transdifferentiation of hair follicle stem cells into corneal epithelial-like cells. Stem Cells 27:642-652.

9. Inatomi T, Nakamura T, Koizumi N, Sotozono C, Yokoi N, et al. (2006) Midterm results on ocular surface reconstruction using cultivated autologous oral mucosal epithelial transplantation. Am J Ophthalmol141: 267-275.[Crossref]

10. Satake Y, Dogru M, Yamane GY, Kinoshita S, Tsubota K, et al. (2008) Barrier function and cytologic features of the ocular surface epithelium after autologous cultivated oral mucosal epithelial transplantation. Arch Ophthalmol 126:23-28.

11. Uccelli A, Moretta L, Pistoia V (2006) Immunoregulatory function of mesenchymal stem cells. Eur J Immunol36: 2566-2573.[Crossref]

12. Westerweel PE, Verhaar MC (2008) Directing myogenic mesenchymal stem cell differentiation. Circ Res 103: 560-561.[Crossref]

13. Kurpinski K, Lam H, Chu J, Wang A, Kim A, et al. (2010) Transforming growth factorbeta and notch signaling mediate stem cell differentiation into smooth muscle cells. Stem Cells 28: 734-742.[Crossref]

14. Ye J, Yao K, Kim JC (2006) Mesenchymal stem cell transplantation in a rabbit corneal alkali burn model: engraftment and involvement in wound healing. Eye (Lond) 20: 482-490.[Crossref]

15. Wu Y, Chen L, Scott PG, Tredget EE (2007) Mesenchymal stem cells enhance wound healing through differentiation and angiogenesis. Stem Cells 25: 2648-2659.[Crossref]

16. Ma Y, Xu Y, Xiao Z, Yang W, Zhang C, et al. (2006) Reconstruction of chemically burned rat corneal surface by bone marrow-derived human mesenchymal stem cells. Stem Cells 24: 315-321.[Crossref]

17. Reinshagen H, Auw-Haedrich C, Sorg RV, Boehringer D, Eberwein P, et al. (2011) Corneal surface reconstruction using adult mesenchymal stem cells in experimental limbal stem cell deficiency in rabbits. Acta Ophthalmol 89:741-748.

18. Friedenstein AJ, Deriglasova UF, Kulagina NN, Panasuk AF, Rudakowa SF, et al (1974) Precursors for fibroblasts in different populations of hematopoietic cells as detected by the in vitro colony assay method. ExpHematol2: 83-92.[Crossref]

19. Nithya J, Kumar PR, Tilak P, Leena J, Sreenivasan K, et al. (2011) Intelligent thermoresponsive substrate from modified overhead projection sheet as a tool for construction and support of cell sheets in vitro. Tissue Eng Part C Methods 17:181-191.

20. Sitalakshmi G, Sudha B, Madhavan HN, Vinay S, Krishnakumar S, et al. (2009) Ex vivo cultivation of corneal limbal epithelial cells in a thermoreversible polymer (Mebiol Gel) and their transplantation in rabbits: an animal model. Tissue Eng Part A 15:407-415.

21. Secker GA, Daniels JT (2008)Limbal epithelial stem cells of the cornea

22. Schlötzer-Schrehardt U1, Kruse FE (2005) Identification and characterization of limbal stem cells. Exp Eye Res 81: 247-264.[Crossref] 
23. Sangwan VS (2001) Limbal stem cells in health and disease. Biosci Rep 21: 385-405. [Crossref]

24. Tsai RJ, Li LM, Chen JK (2000) Reconstruction of damaged corneas by transplantation of autologous limbal epithelial cells. $N$ Engl J Med 343: 86-93.[Crossref]

25. Krause DS, Theise ND, Collector MI, Henegariu O, Hwang S, et al. (2001) Multiorgan, multi-lineage engraftment by a single bone marrow-derived stem cell. Cell 105:369-377.

26. Tremain N, Korkko J, Ibberson D, Kopen GC, DiGirolamo C, et al. (2001) MicroSAGE analysis of 2,353 expressed genes in a single cell-derived colony of undifferentiated human mesenchymal stem cells reveals mRNAs of multiple cell lineages. Stem Cells 19:408-418.

27. Alhadlaq A, Mao JJ (2004) Mesenchymal stem cells: isolation and therapeutics. Stem Cells Dev 13: 436-448.[Crossref]

28. Orlic D, Kajstura J, Chimenti S, Jakoniuk I, Anderson SM, et al. (2001) Bone marrow cells regenerate infarcted myocardium. Nature 410:701-705.

29. Lee JW, Fang X, Gupta N, Serikov V, Matthay MA (2009) Allogeneic human mesenchymal stem cells for treatment of E. coli endotoxin-induced acute lung injury in the ex vivo perfused human lung. Proc Natl Acad Sci U S A 106: 16357-16362.[Crossref]

30. Wong AP, Keating A, Lu WY, Duchesneau P, Wang X, et al. (2009) Identification of a bone marrow-derived epithelial-like population capable of repopulating injured mouse airway epithelium. J Clin Invest 119:336-348.

31. Wang G, Bunnell BA, Painter RG, Quiniones BC, Tom S, et al. (2005) Adult stem cells from bone marrow stroma differentiate into airway epithelial cells: potential therapy for cystic fibrosis. Proc Natl Acad Sci U S A 102:186-191.

32. PÄfunescu V, Deak E, Herman D, Siska IR, TÄ fnasie G, et al. (2007) In vitro differentiation of human mesenchymal stem cells to epithelial lineage. $\mathrm{J} \mathrm{Cell} \mathrm{Mol} \mathrm{Med}$ 11: 502-508.[Crossref]

33. Singaravelu K, Padanilam BJ (2009) In vitro differentiation of MSC into cells with a renal tubular epithelial-like phenotype. Ren Fail 31: 492-502.[Crossref]

34. Lapi S, Nocchi F, Lamanna R, Passeri S, Iorio M, et al. (2008) Different media and supplements modulate the clonogenic and expansion properties of rabbit bone marrow mesenchymal stem cells. BMC Res Notes 1: 53.[Crossref]

35. Timper K, Seboek D, Eberhardt M, Linscheid P, Christ-Crain M, et al. (2006) Human adipose tissue-derived mesenchymal stem cells differentiate into insulin, somatostatin, and glucagon expressing cells. BiochemBiophys Res Commun 341:1135-1140.

36. Arufe MC, De la Fuente A, Fuentes-Boquete I, De Toro FJ, Blanco FJ (2009) Differentiation of synovial CD-105(+) human mesenchymal stem cells into chondrocyte-like cells through spheroid formation. J Cell Biochem 108:145-155.

37. Polisetti N, Chaitanya VG, Babu PP, Vemuganti GK (2010) Isolation, characterization and differentiation potential of rat bone marrow stromal cells. Neurol India 58:201-208.

38. Dominici M, Le Blanc K, Mueller I, Slaper-Cortenbach I, Marini F, et al. (2006) Minimal criteria for defining multipotent mesenchymal stromal cells. The Internationa Society for Cellular Therapy position statement. Cytotherapy 8:315-317.
39. Sudha B, Sitalakshmi G, Iyer GK, Krishnakumar S (2008) Putative stem cell markers in limbal epithelial cells cultured on intact $\&$ denuded human amniotic membrane. Indian J Med Res 128:149-156.

40. Wiesmann A, Bühring HJ, Mentrup C, Wiesmann HP (2006) Decreased CD90 expression in human mesenchymal stem cells by applying mechanical stimulation. Head Face Med 2: 8.[Crossref]

41. Dravida S, Pal R, Khanna A, Tipnis SP, Ravindran G, et al. (2005) The transdifferentiation potential of limbal fibroblast-like cells. Brain Res Dev Brain Res 160: 239-251.[Crossref]

42. Ahmad S, Stewart R, Yung S, Kolli S, Armstrong L, et al. (2007) Differentiation of human embryonic stem cells into corneal epithelial-like cells by in vitro replication of the corneal epithelial stem cell niche. Stem Cells 25: 1145-1155.[Crossref]

43. Shimmura S, Miyashita H, Higa K, Yoshida S, Shimazaki J, et al. (2006) Proteomic analysis of soluble factors secreted by limbal fibroblasts. Mol Vis 12: 478-484. [Crossref]

44. Homma R, Yoshikawa H, Takeno M, Kurokawa MS, Masuda C, et al. (2004) Induction of epithelial progenitors in vitro from mouse embryonic stem cells and application for reconstruction of damaged cornea in mice. Invest Ophthalmol Vis Sci 45:4320-4326.

45. Marshall GE, Konstas AG, Lee WR (1993) Collagens in ocular tissues. $\mathrm{Br} J$ Ophthalmol77: 515-524.[Crossref]

46. Ljubimov AV, Burgeson RE, Butkowski RJ, Michael AF, Sun TT, et al. (1995) Human corneal basement membrane heterogeneity: topographical differences in the expression of type IV collagen and laminin isoforms. Lab Invest 72:461-473.

47. Schlötzer-Schrehardt U, Dietrich T, Saito K, Sorokin L, Sasaki T, et al. (2007) Characterization of extracellular matrix components in the limbal epithelial stem cell compartment. Exp Eye Res 85: 845-860.[Crossref]

48. Murakami J, Nishida T, Otori T (1992) Coordinated appearance of beta 1 integrins and fibronectin during corneal wound healing. J Lab Clin Med 120: 86-93.[Crossref]

49. Li DQ, Tseng SC (1995) Three patterns of cytokine expression potentially involved in epithelial-fibroblast interactions of human ocular surface. J Cell Physiol163: 61-79. [Crossref]

50. Yu L, Ge J, Wang Z, Huang B, Yu K, et al. (2001) The preliminary experimental study of induced differentiation of embryonic stem cells into corneal epithelial cells. Yan KeXиe Bao 17:138-143.

51. Jiang TS, Cai L, Ji WY, Hui YN, Wang YS, et al. (2010) Reconstruction of the corneal epithelium with induced marrow mesenchymal stem cells in rats. Mol Vis 16: 1304 1316.[Crossref]

52. Kay ED, Cheung CC, Jester JV, Nimni ME, Smith RE (1982) Type I collagen and fibronectin synthesis by retrocorneal fibrous membrane. Invest Ophthalmol Vis Sci 22 200-212.[Crossref]

53. Nakayasu K, Tanaka M, Konomi H, Hayashi T (1986) Distribution of types I, II, III, IV and V collagen in normal and keratoconus corneas. Ophthalmic Res 18: 1-10.[Crossref]

Copyright: (C2017 Mathews S. This is an open-access article distributed under the terms of the Creative Commons Attribution License, which permits unrestricted use, distribution, and reproduction in any medium, provided the original author and source are credited. 